\title{
Use of a novel valve stent for transcatheter pulmonary valve replacement: An animal study
}

\author{
Gang-Jun Zong, MD, PhD, ${ }^{\text {a }}$ Yuan Bai, MD, ${ }^{a}$ Hai-Bin Jiang, MD, ${ }^{a}$ Wei-Ping Li, MD, PhD, ${ }^{b}$ Hong Wu, MD, PhD, \\ Xian-Xian Zhao, MD, PhD, and Yong-Wen Qin, $\mathrm{MD}, \mathrm{PhD}^{\mathrm{a}}$
} Objective: The goal of this study was to evaluate valvular functionality after transcatheter pulmonary valve
replacement in sheep using a novel pulmonary valve stent.

\begin{abstract}
Methods: Fresh porcine pericardium cross-linked with $0.6 \%$ glutaraldehyde was treated with L-glutamine to eliminate glutaraldehyde toxicity and sutured onto a valve ring before mounting on a nitinol stent to construct the pulmonary valve stent. Percutaneous femoral vein transcatheter pulmonary valve replacement was performed with the newly constructed valve stent. Pulmonary valve stents were implanted in 10 healthy sheep (6 males and 4 females) weighing an average of $25.7 \pm 4.1 \mathrm{~kg}$. Color Doppler echocardiography, 64-row computed tomography, and direct catheter examination were used to assess valvular function.
\end{abstract}

Results: Implantation was successful in 8 sheep. Shortly after surgery, all artificial valve stents exhibited normal open and close functionality and no stenosis or insufficiency. Heart rate was slightly elevated at this time, while all other hemodynamic parameters were normal. Six-month follow-up revealed no evidence of valve stent dislocation and normal valvular and cardiac functionality. There was no evidence of stent fracture. Repeated valve stent implantation was well tolerated as indicated by good valvular functionality 2 months postdelivery.

Conclusion: The novel pulmonary valve stent described herein can be delivered via percutaneous femoral vein transcatheter implantation and is highly efficacious at 6 months postdelivery. Furthermore, repeated valve stent replacement was successful.

From the earliest transcatheter valve replacement experimental study performed by Andersen and colleagues in 1992, ${ }^{1}$ to Bonhoeffer and colleagues' pilot study of percutaneous pulmonary valve replacement in a right ventricle-to-pulmonary artery prosthetic conduit with valve dysfunction in $2000,{ }^{2}$ pulmonary valve replacement technology has steadily advanced. ${ }^{3-5}$ Clinically, this technique appears to offer significant benefits over standard surgical procedures for patients with congenital heart diseases requiring additional surgical intervention. ${ }^{6,7}$ Not only is the process efficacious and less traumatic, but the duration of hospital stay is shortened. ${ }^{6}$

Despite the fact that the use of percutaneous pulmonary valve transplantation has been readily adopted, various problems associated with stent implantation per se have been reported. These include stent fracture, valve dislocation, and restenosis. ${ }^{8-12}$ In addition, as outlined by Attmann and colleagues, ${ }^{13}$ currently available stents are not suitable for use in all prospective patients due to anatomic variability. Hence there is a definite need for continued development

\footnotetext{
From the Departments of Cardiology and Ultrasonography, ${ }^{\mathrm{b}}$ Changhai Hospital, Second Military Medical University, Shanghai, China.

This research was supported by the National High Technology Research and Development Program of China.

G.-J. Zong and Y. Bai contributed equally to this study.

Received for publication July 31, 2008; revisions received Nov 18, 2008; accepted for publication Dec 25, 2008

Address for reprints: Yong-Wen Qin, MD, PhD, Department of Cardiology, Changhai Hospital, Second Military Medical University, Shanghai, 200433, China (E-mail: ywqinsmmu@yahoo.cn).

J Thorac Cardiovasc Surg 2009;137:1363-9

$0022-5223 / \$ 36.00$

Copyright $\subset 2009$ by The American Association for Thoracic Surgery

doi:10.1016/j.jtcvs.2008.12.025
}

and refinement with regards to the application of this relatively recent technique.

Here we report on the design and use of a novel valve stent device for transcatheter pulmonary valve replacement. This study was performed using an ovine experimental model. Immediate postoperative functional analysis was assessed using color echocardiography, and a comprehensive follow-up evaluation was performed at 6 months using color echocardiography, 64-row computed tomography (CT), and direct catheter examination.

\section{METHODS}

\section{Valve Stent Construction}

The valve stent was constructed using an artificial valve and a conduitshaped stent. The artificial stent was constructed from a valve leaflet and a valve ring. The valve ring was made of supermalleable nitinol wire (Shanghai Malleable Alloy Company, Shanghai, China) with a radial diameter of $0.25 \mathrm{~mm}$, bent into 3 crescent shapes, and connected by a nitinol holder (see Figure 1, $A$ ). Porcine pericardium was used for valve leaflet creation following removal of surface fat tissue, agitated digestion with $0.01 \%$ trypsin for 8 hours, subsequent cross-linking with $0.6 \%$ glutaraldehyde for 36 hours, and, finally, repeated washing with $2 \%$ L-glutamine (to eliminate glutaraldehyde toxicity). Pericardium tissue was trimmed into 3 identically shaped valve leaflets according to the valve model profile and sutured onto the valve ring using $7-0$ polypropylene thread (Johnson and Johnson, New Brunswick City, NJ). The attached side was denoted as the attachment margin and the nonattached side, the margo liber. The completed artificial valve is depicted in Figure 1, $B$.

The conduit-shaped stent was constructed with supermalleable nitinol wire with a diameter of $0.18 \mathrm{~mm}$ and was comprised of 3 parts: the head, neck, and body. The head portion was proximal to the heart end, slightly protruded, and trumpet shaped. The neck portion was thinner and connected the head portion with the body portion. The body portion was straight and tubular shaped.

The artificial valve was fixed inside the conduit-shaped stent, with the arc tips facing toward the top of the head portion and the sides attached to the 


\section{Abbreviations and Acronyms \\ $\mathrm{CT}=$ computed tomography \\ $\mathrm{DSA}=$ digital subtraction angiography}

neck portion, both of which were sutured with 5-0 polypropylene thread (Figure 1, $C$ shows the completed valve stent). The valve stent was preserved in $60 \%$ ethanol, sterilized with $75 \%$ ethanol for 12 hours, and washed 3 times with saline prior to placement. Figure 2, $A$ and $B$, shows the valved stent crimped by hand and then loaded into a 14-French sheath, respectively.

\section{Animals \\ Animal studies were approved by the local hospital ethics committee. All animals received care in compliance with the Guide for the Care and Use of Laboratory Animals (www.nap.edu/catalog/5140.html). Ten healthy sheep (6 males and 4 females), 12 to 16 months old and weighing an average of $25.7 \pm 4.1 \mathrm{~kg}$, were used. Preoperative electrocardiogram, chest film, and color echocardiographic examinations revealed no abnormalities. No car- diac murmurs were detected. Animals were fasted and water deprived for 8 hours before surgery. Anesthesia was initiated by intramuscular injection of ketamine $(10 \mathrm{mg} / \mathrm{kg}$ body weight), followed by intravenous injection of $10 \mathrm{~mL}$ of $2.5 \%$ pentobarbital sodium. Hair was removed from the precor- dial region and the inner sides of the extremities.}

\section{Valve Stent Implantation and Postoperative Treatment}

After sterilizing the skin in the inguinal region, a 6-French leak-proof sheath was introduced percutaneously via the left femoral vein. An incision was made through the right inguinal skin and subcutaneous tissue, and the right femoral vein was subsequently exposed and punctured with a 7-French leak-proof sheath. Heparin $(1.5 \mathrm{mg} / \mathrm{kg})$ was introduced via the sheath. A 6-French pigtail catheter (Cordis, Johnson and Johnson, New Brunswick City, NJ) was introduced through the right femoral vein sheath, and imaging of the right ventricle and pulmonary valve was performed using digital subtraction angiography (DSA) (Siemens, Munich, Germany; Figure 3, A). Pressure values for the right ventricle and main pulmonary artery were also determined. The pulmonary valve was identified, and its position was marked according to imaging results. After measuring the radius of the pulmonary valve, a valve stent of appropriate size was selected and loaded into a 14-French sheath. A stent size larger than the measured annulus was selected to ensure the avoidance of paravalvular leaks and in consideration of the growth of the young sheep. The delivery route was established by introducing a steel guide wire into the distal segment of the left or right pulmonary valve via the pigtail catheter (see Figure $3, B$ ). After the pigtail catheter was removed, a 14-French delivery sheath with an expandable stub was deployed into the main pulmonary artery via the guide wire (Shanghai ShapeMemory Alloys Material Limited Company, Shanghai, China; Figure 3, C). The expandable stub and steel guide wire were then removed, and the 14French sheath carrying the valve stent was connected with the delivery sheath. The stent was inserted into the delivery sheath and the neck advanced (under the DSA) to the previously marked position of the pulmonary valve (Figure 3,D). After confirming that the stent had been delivered to the optimal position, the delivery sheath was retracted to release the stent (Figure 3, $E$ ). The delivery sheath was subsequently removed and the right femoral vein sutured. Imaging of the artificial pulmonary valve and the right ventricle was performed by deploying a pigtail catheter via the left femoral vein (Figure 3, $F)$. Pressure values were recorded for the right ventricle and the main pulmonary artery. The catheter and right femoral vein sheath were removed. Iohexol, up to $50 \mathrm{~mL}$, was used as the contrast dye in the procedure.

All sheep received postoperative intramuscular injections of penicillin $(800,000 \mathrm{U})$ and subcutaneous injections of heparin (2500 IU) for 3 days. Oral aspirin ( $3 \mathrm{mg} / \mathrm{kg}$ body weight) was given for 60 days.

\section{Evaluation of Short-Term Efficacy of Valve Stent Implantation}

Immediately after implantation, chest color Doppler ultrasonography was performed to assess right ventricular function and the hemodynamic function of the artificial valve.

\section{Evaluation of Valve Stent Implantation After 6 Months}

All surviving sheep underwent chest color Doppler ultrasonography, 64-row enhanced CT, and DSA 6 months after stent implantation. The right ventricle and artificial valve were examined to assess functionality and hemodynamics.

One randomly selected sheep was killed by femoral artery bleeding. The heart was collected, the right ventricle incised, and the position of the valve stent noted. The stent was examined using electron microscopy.
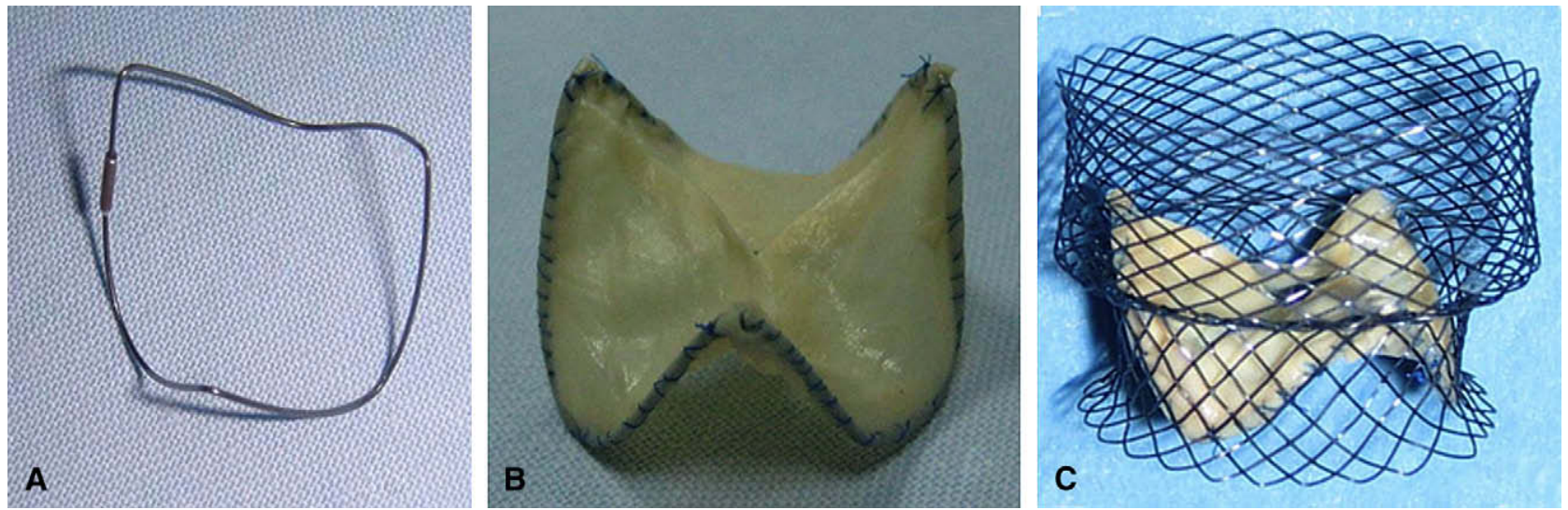

FIGURE 1. Pulmonary valve stent construction. A, The valve ring was made of supermalleable nitinol wire bent into 3 arc shapes. B, Three valve leaflets were constructed by trimming porcine pericardium. The valve leaflets were sutured onto the valve ring. One side was denoted the attachment region and the other, margo libra. C, The conduit-shaped stent comprised of the head, neck, and body. The head portion was proximal to the heart end, slightly protruded, and trumpet shaped. The neck portion was thinner and connected the head portion with the body portion. The body portion was a straight tubular shape. The artificial valve was placed within the tubular stent. 

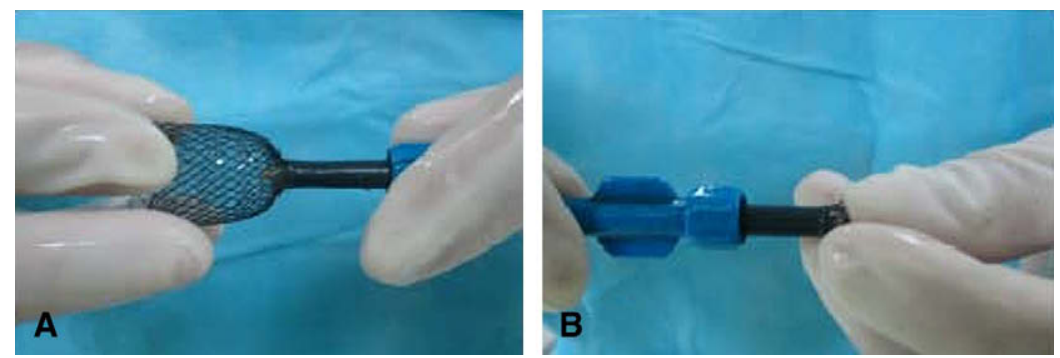

FIGURE 2. Placement of valved stent into sheath. A, The valved stent was crimped by hand to load into a 14-French sheath. B, The valved stent completely crimped into the sheath.

\section{Efficacy of Repeated Valve Stent Implantation}

Six months after initial implantation, 2 randomly selected surviving sheep had a repeated valve stent implantation via percutaneous DSA at the same location as the initial implantation. The placement process was the same as the initial implantation. Two months after surgery, follow-up color Doppler ultrasonography was performed and valvular function and location examined.

\section{Statistical Analysis}

Means, standard deviations, and minimum and maximums values are given for continuous variables. Changes in heart rate, mean arterial pressure, right ventricular pressure, pulmonary artery pressure, right ventricular volume, right ventricular ejection fraction, transvalvular gradients, and effective orifice areas over time (before implantation, 12 hours after implantation, and 6 months after implantation) were compared using repeated measurements. Moreover, Wilcoxon signed-rank test was performed to compare the difference between the 2 time points postoperation due to nonnormally data. All statistical assessments were 2 -sided and evaluated at the 0.05 level of significant difference. Statistical analyses were performed using SPSS 15.0 statistical software (SPSS Inc, Chicago, IIl).

\section{RESULTS}

\section{Operative Parameters}

Valve stent implantation was not possible in 2 of the 10 sheep. One of these animals had abnormally small
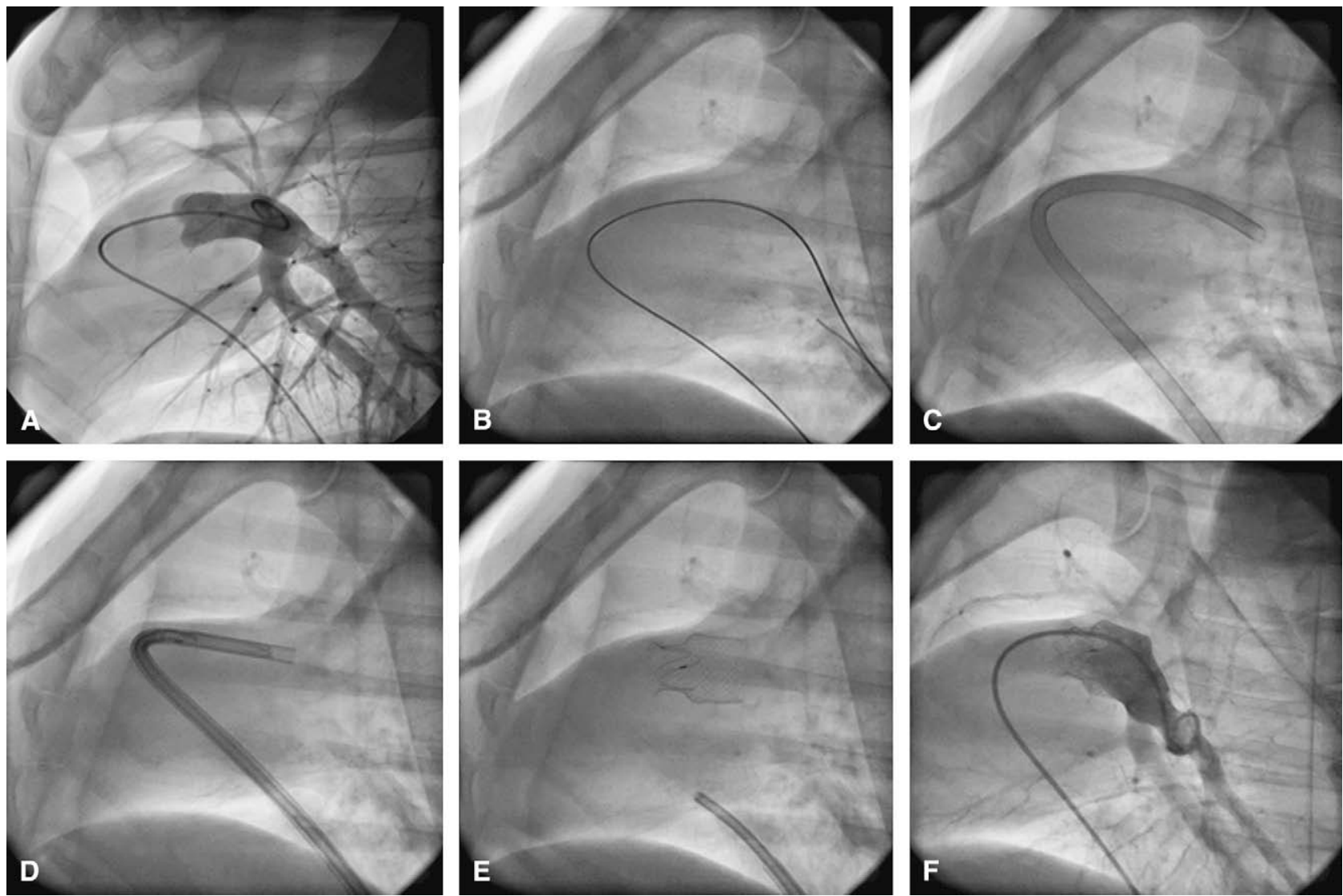

FIGURE 3. Valve stent implantation process (representative images). A, Imaging of the pulmonary valve was performed to measure the pulmonary valve radius and location. B, Steel guide wires were deployed into the left or right pulmonary artery regions to facilitate delivery. C, A 14-French delivery sheath was inserted into the pulmonary artery. D, The neck portion of the stent was delivered to the previously noted location of the pulmonary valve. E, The delivery sheath was retracted and the stent released. F, Image of the artificial pulmonary valve revealing good placement and no regurgitation. 
femoral vein, and the other died due to excessive anesthesia. Valve stent implantation was successful in the 8 other sheep. The mean diameter of the pulmonary annulus was $14.2 \pm$ $1.4 \mathrm{~mm}$ and $15.4 \pm 1.3 \mathrm{~mm}$ as revealed by Doppler ultrasound and angiography, respectively. The mean stent diameter was $19.8 \pm 1.7$ (range: $18-22 \mathrm{~mm}$ ). Mean surgery duration was $57.0 \pm 7.8$ minutes (range: $48-70$ minutes). The mean $\mathrm{x}$-ray exposure time was $10.6 \pm 2.3$ minutes (range: 7.2-13.4 minutes; Table 1).

\section{Short-Term Efficacy Evaluation of Valve Stent Implantation}

In each case, the valve stent was immediately observable under color Doppler ultrasonography following implantation. Artificial valve stents exhibited normal open and close functionality with no evidence of stenosis or insufficiency (data not shown). Heart rate was significantly increased after stent implantation compared with before implantation $(P=.042$, Figure $4, A)$. There were no other differences detected before and immediately after implantation for any of the other heart function markers examined (Figure 4, $B-H$ ).

\section{Efficacy of Valve Stent Implantation After 6 Months}

All sheep exhibited normal open and close valvular functionality after 6 months, with no evidence of stenosis or insufficiency apparent (Figure 5, $A-D$ ). Sixty-four-row CT revealed accurate placement of the devices. Animals had a weight gain of 8.2 to $13.5 \mathrm{~kg}$. All heart function markers were normal (ie, not different to preimplantation values; Figure $4, A-H)$. In all animals, no stent fracture, valve deformation or dislocation problems, or paravalvular leakage was noted. Histologic dissection revealed a complete stent with no evidence of fracture. Electron microscopy revealed that

TABLE 1. Surgical information of implantations performed on experimental ewes

\begin{tabular}{|c|c|c|c|c|c|}
\hline & $\begin{array}{c}\text { Pulmonary } \\
\text { annulus } \\
\text { US (mm) }\end{array}$ & $\begin{array}{c}\text { Pulmonary } \\
\text { annulus } \\
\text { angiography } \\
\text { (mm) }\end{array}$ & $\begin{array}{c}\text { Diameter } \\
\text { of stent } \\
(\mathbf{m m})\end{array}$ & $\begin{array}{c}\text { Operation } \\
\text { time } \\
(\mathrm{min})\end{array}$ & $\begin{array}{c}\text { Radiograph } \\
\text { exposure } \\
\text { time (min) }\end{array}$ \\
\hline \multicolumn{6}{|l|}{ ID } \\
\hline 1 & 13.5 & 14.6 & 18 & 54 & 9.2 \\
\hline 2 & 12.2 & 13.2 & 18 & 65 & 11.1 \\
\hline 3 & 16.3 & 17.2 & 22 & 70 & 13.4 \\
\hline 4 & 14.3 & 15.4 & 20 & 50 & 12.5 \\
\hline 5 & 15.3 & 16.7 & 22 & 48 & 7.2 \\
\hline 6 & 12.4 & 14.2 & 18 & 62 & 12.1 \\
\hline 7 & 15.2 & 16.1 & 20 & 53 & 7.9 \\
\hline 10 & 14.6 & 15.8 & 20 & 54 & 11.5 \\
\hline Mean & 14.23 & 15.40 & 19.75 & 57.00 & 10.61 \\
\hline SD & 1.44 & 1.34 & 1.67 & 7.76 & 2.25 \\
\hline Minimum & 12.2 & 13.2 & 18 & 48 & 7.2 \\
\hline Maximum & 16.3 & 17.2 & 22 & 70 & 13.4 \\
\hline
\end{tabular}

$S D$, Standard deviation; US, ultrasound. the stent was completely covered with endothelial cells (see Figure 6, $A$ and $B$ ).

\section{Repeated Valve Stent Implantation}

Ultrasonography revealed normal valvular open and close function 2 months after repeated transplantation in both sheep. One sheep exhibited mild pulmonary regurgitation (Figure 7, A). Regurgitation was not apparent in the other animal, cardiac function was normal, and there was no evidence of valve stenosis (Figure $7, B$ ).

\section{DISCUSSION}

Surgical reconstruction of the right ventricular outflow tract, including valve implantation and pulmonary valve replacement or repair, is clinically efficacious. ${ }^{14}$ However, biologic valve deterioration often necessitates repeated cardiopulmonary bypass surgery. ${ }^{15}$ To circumvent the risks associated with multiple cardiopulmonary bypass surgeries, percutaneous valve replacement has been developed in recent years, ${ }^{16}$ providing patients with an alternative option. In this study, we performed percutaneous femoral vein implantation of the sheep pulmonary valve with a newly designed pulmonary valve stent. The objective of our study was to evaluate whether transcatheter implantation of the novel pulmonary valve stent was achievable and to observe implantation efficacy after 6 months. Repeated pulmonary valve stent implantation was also performed. Implantation of the device was found to be highly successful and efficacious at 6 months postsurgery. Repeated implantation was well tolerated.

The conduit-shaped stent developed in this study required only 1 nitinol wire to be constructed without a connector, exhibited good flexibility, and was capable of adapting to the vessel after implantation. Electron microscope examination at 6 months postimplantation revealed that the stent was fully covered by endothelial cells, evidencing complete adherence. Because the intersecting region of the woven stent allows vascular contraction and mild diastolic movement, the likelihood of stent fracture should be reduced. The fact that no cases of stent fracture were observed after 6 months supports this assertion. The trumpet-shaped head portion of the stent consolidated placement at the pulmonary orifice, and the adjoining, slightly thinner neck portion facilitated increased overall stent flexibility and prevented stent deformation when the trumpet-shaped opening was pressured. This design is capable of eliminating valve deformation and dislocation problems associated with the use straight tubular stents, arising from compression at the pulmonary orifice. The body portion was conduit-shaped, allowing for greater fixation due to the increased stent diameter. Because the stent shape was well matched with the peripheral valve configuration, the pulmonary valve was compressed between the stent and the right ventricle wall, thus preventing perivalvular leakage. This was substantiated through imaging via color Doppler ultrasonography. 

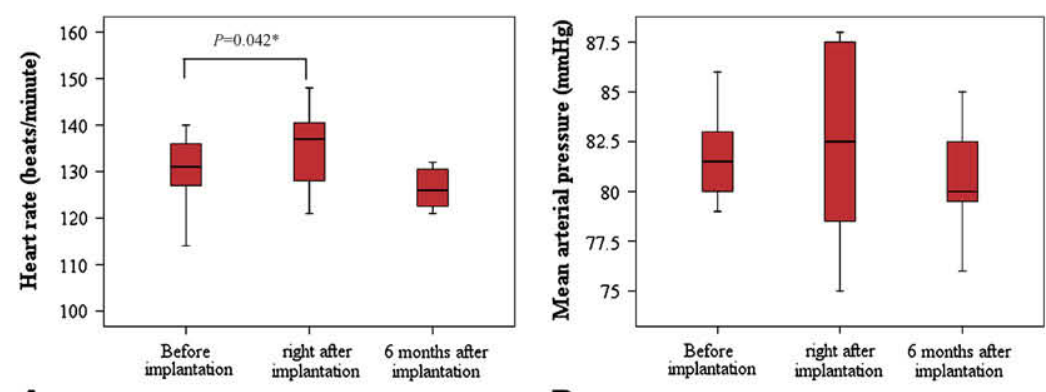

A

time

B

time
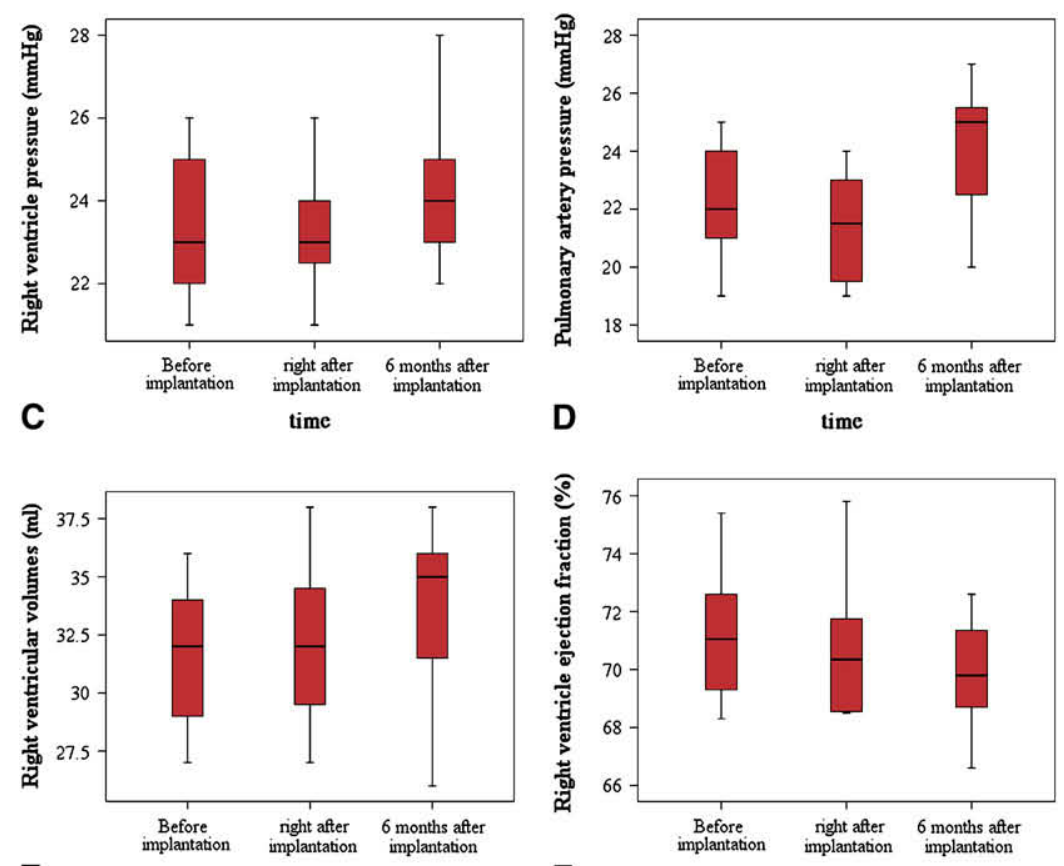

E

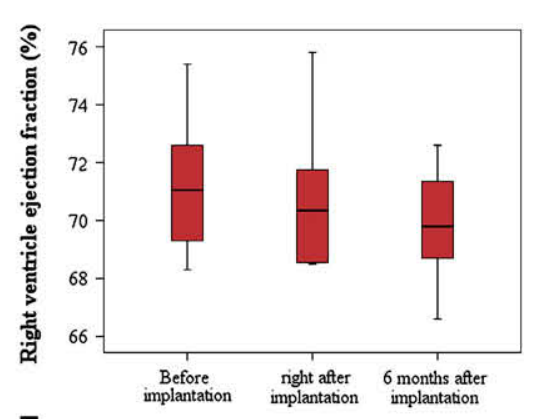

$\mathbf{F}$

time

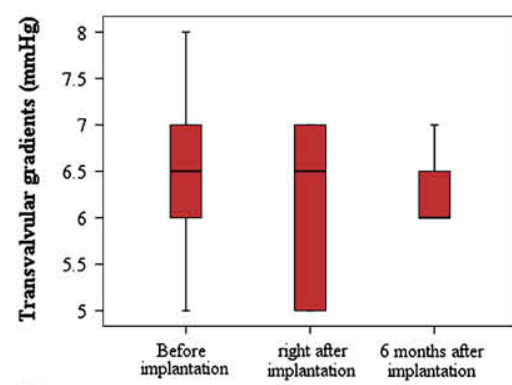

G

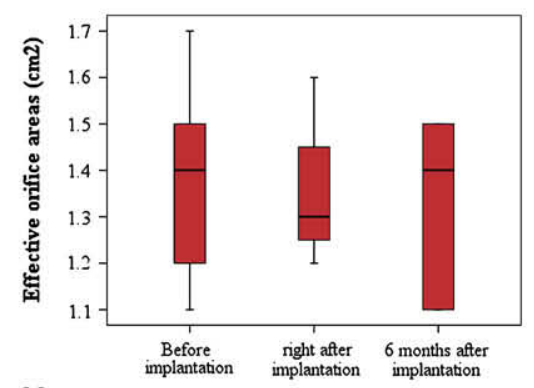

H

time

FIGURE 4. Heart function and hemodynamic markers before, immediately after, and 6 months after implantation. Heart rate (A), mean arterial pressure (B), right ventricle pressure $(C)$, pulmonary artery pressure $(D)$, right ventricular volumes $(E)$, right ventricle ejection fraction $(F)$, transvalvular gradients $(G)$, and effective orifice areas $(\mathrm{H})$ were assessed. $* P<.05$ between the indicated means.

In this study, the artificial valve was sutured onto a nitinol valve ring, as opposed to direct suture into the stent. This made suturing of the valve into the conduit-shaped stent easier and firmer and resulted in the artificial valve being less susceptible to deformation. This also guaranteed that the artificial valve remained on a flat surface, which better prevents valve insufficiency and dislocation from occurring. We found that valvular and hemodynamic functions were normal 6 months postimplantation. Furthermore, there was no evidence of increased thrombotic development on valve ring structure following conventional anticoagulation therapy.

With regards to the materials used for artificial pulmonary valve construction, previous studies have typically reported use of the bovine jugular vein valve ${ }^{17,18}$ and 


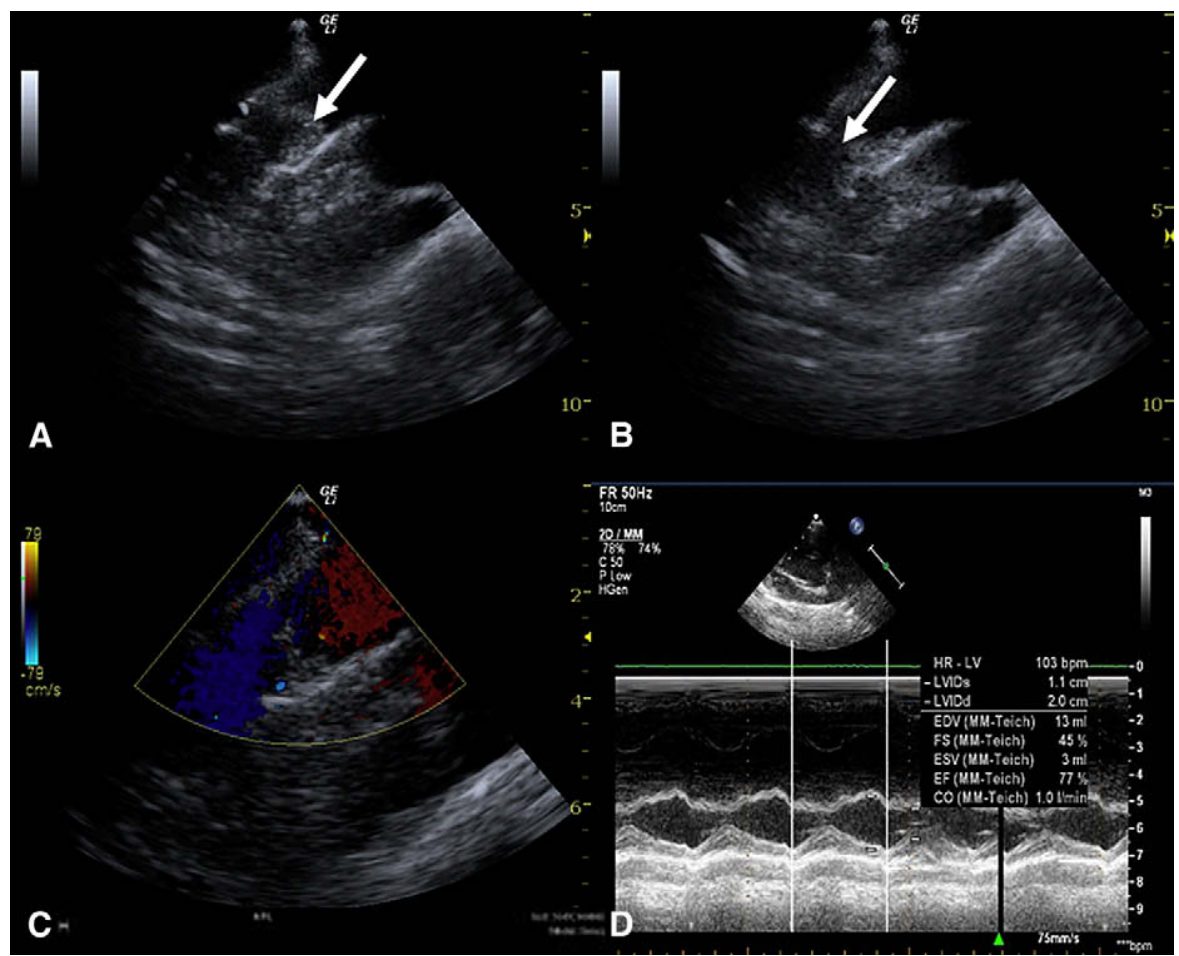

FIGURE 5. Pulmonary artery valve stent 6 months after implantation: color ultrasonography and computed tomography examination findings from a representative animal. A, Artificial valve opening (white arrow). B, Artificial valve closing (white arrow). C, Color Doppler ultrasonography revealed no patterns of blood passing or regurgitation. $D$, Right ventricular ejection fraction.

polytetrafluoroethylene valve. ${ }^{19}$ The use of porcine pericardium as a surgical biologic valve has a long history. We used porcine pericardium as the material for valve construction in this study, applying surgical procedures to establish the pericardium as a valve sutured onto a valvular ring. Porcine pericardium not only was easily obtained, but also had larger valve diameter.

The design of the artificial valve was inspirited by biologic valves in vivo. The function of valves was determined by the design of valve ring. In combination with the trumpetshaped stent that provides a strong anchor, the valved stent is functional as well. The woven design of the stent increases compliance to avoid damage from contraction of the heart. The design of the valve ring may assist in preventing postimplantation deformity of the valve. The trumpet shape and use of a slightly oversized stent ensure solid anchoring of the stent and also avoid paravalvular leakage.

The surgical implantation technique used in this study was similar to widely used techniques for intracoronary stent implantation but different from implantation techniques involving the fixation of the valve stent on the tip of a delivery sheath. Given that the stent-fixed delivery sheath is hard and less flexible, damage to the heart may occur during the curved passage from the inferior vena cava to the main

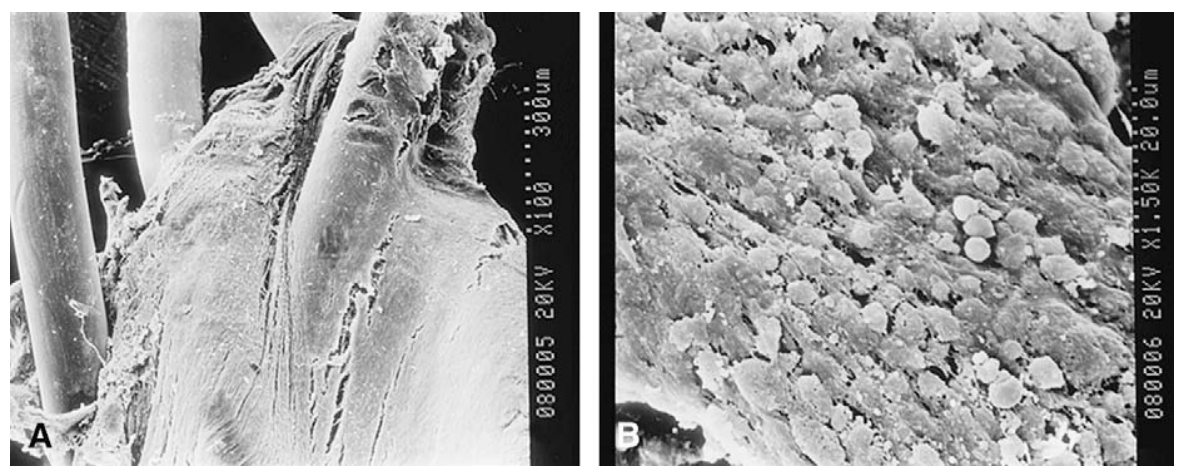

FIGURE 6. Six-month postoperative electron microscopy images of a stent. A, Nitinol wire covered by endothelial cells (magnification $100 \times$ ). B, The stent was completely covered by neatly arranged endothelial cells (magnification $1500 \times$ ). 


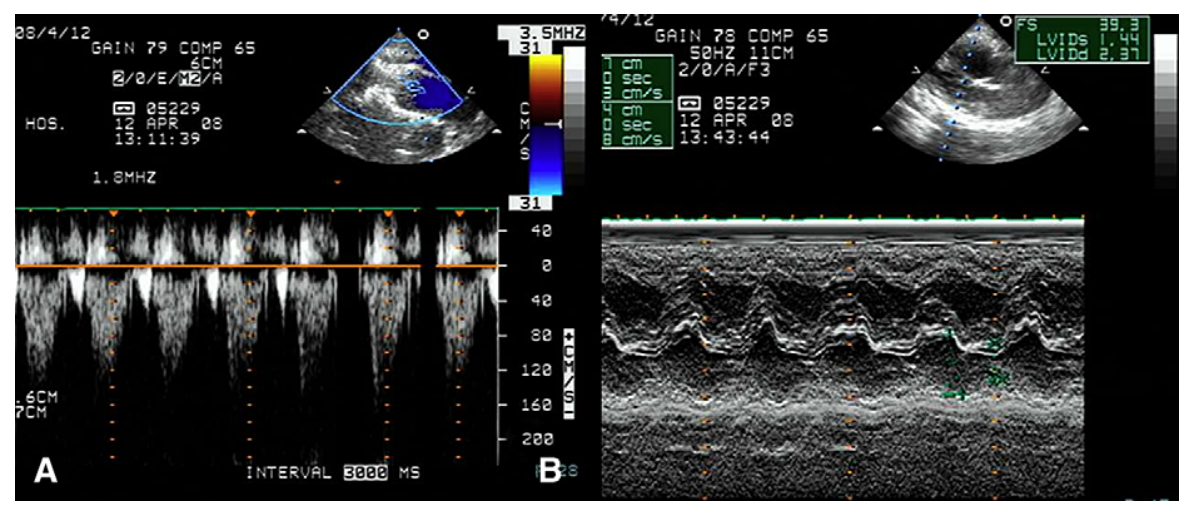

FIGURE 7. Color Doppler ultrasonography examinations were performed 2 months after the second valve stent implantation. A, Spectral of the pulmonary valve revealed mild regurgitation. B, Motion mode ultrasonography revealed normal cardiac function.

pulmonary artery. In this study, we first introduced the delivery sheath into the pulmonary artery and then pushed the device through the sheath and into the pulmonary artery. This allowed for safer passage, with no significant increase in $\mathrm{x}$ ray exposure time.

The life expectancy of biologic valves is an issue of significant concern. Once a valve deteriorates, replacement implantation becomes necessary. Hence it is critical that valve stents are amenable to repeated implantation. The valve stent described in the current study exhibited good vascular compliance upon secondary push delivery implantation and readily overlapped with the initial stent. No significant complications were detected following repeated implantation.

This study had several limitations. First, the valve stent could not be completely retrieved once released. Thus, further modifications to the delivery system are needed to provide flexibility in cases of suboptimal placement and/or stent size incompatibility. Such modifications will increase the safety and reliability of this procedure. Second, the animal cohort size was small and the follow-up time short. Last, the use of a single sheep for histologic evaluation and the lack of quantitative assessment of calcification are also limitations. Additional studies, with larger cohorts and longer follow-up durations, are needed to provide sufficient reference data for potential clinical application.

\section{References}

1. Andersen HR, Knudsen LL, Hasenkam JM. Transluminal implantation of artificial heart valves. Description of a new expandable aortic valve and initial results with implantation by catheter technique in closed chest pigs. Eur Heart J. 1992;13:704-8.

2. Bonhoeffer P, Boudjemline Y, Saliba Z, Merckx J, Aggoun Y, Bonnet D, et al. Percutaneous replacement of pulmonary valve in a right-ventricle to pulmonary-artery prosthetic conduit with valve dysfunction. Lancet. 2000;356:1403-5.

3. Feinstein JA, Kim N, Reddy VM, Perry SB. Percutaneous pulmonary valve placement in a 10-month-old patient using a hand crafted stent-mounted porcine valve. Catheter Cardiovasc Interv. 2006;67:644-9.
4. Garay F, Webb J, Hijazi ZM. Percutaneous replacement of pulmonary valve using the Edwards-Cribier percutaneous heart valve: first report in a human patient. Catheter Cardiovasc Interv. 2006;67:659-62.

5. Coats L, Bonhoeffer P. New percutaneous treatments for valve disease. Heart. 2007;93:639-44.

6. Nordmeyer J, Coats L, Bonhoeffer P. Current experience with percutaneous pulmonary valve implantation. Semin Thorac Cardiovasc Surg. 2006;18: 122-5.

7. Lurz P, Coats L, Khambadkone S, Nordmeyer J, Boudjemline Y, Schievano S, et al. Percutaneous pulmonary valve implantation: impact of evolving technology and learning curve on clinical outcome. Circulation. 2008;117:1964-72.

8. Khambadkone S, Coats L, Taylor A, Boudjemline Y, Derrick G, Tsang V, et al. Percutaneous pulmonary valve implantation in humans: results in 59 consecutive patients. Circulation. 2005;112:1189-97.

9. Khambadkone S, Nordmeyer J, Bonhoeffer P. Percutaneous implantation of the pulmonary and aortic valves: indications and limitations. J Cardiovasc Med (Hagerstown). 2007;8:57-61.

10. Nordmeyer J, Lee TY, Bonhoeffer P. Percutaneous pulmonary valve implantation: a 5-year projection. Am Heart Hosp J. 2006;4:205-6.

11. Schievano S, Petrini L, Migliavacca F, Coats L, Nordmeyer J, Lurz P, et al. Finite element analysis of stent deployment: understanding stent fracture in percutaneous pulmonary valve implantation. J Interv Cardiol. 2007;20:546-54.

12. Kostolny M, Tsang V, Nordmeyer J, Van Doorn C, Frigiola A, Khambadkone S, et al. Rescue surgery following percutaneous pulmonary valve implantation. Eur J Cardiothorac Surg. 2008;33:607-12.

13. Attmann T, Quaden R, Jahnke T, Muller-Hulsbeck S, Boening A, Cremer J, et al. Percutaneous pulmonary valve replacement: 3-month evaluation of self-expanding valved stents. Ann Thorac Surg. 2006;82:708-13.

14. Wells WJ, Arroyo H Jr, Bremner RM, Wood J, Starnes VA. Homograft conduit failure in infants is not due to somatic outgrowth. J Thorac Cardiovasc Surg. 2002;124:88-96.

15. Bouzas B, Kilner PJ, Gatzoulis MA. Pulmonary regurgitation: not a benign lesion Eur Heart J. 2005;26:433-9.

16. Bonhoeffer P, Boudjemline Y, Qureshi SA, Le Bidois J, Iserin L, Acar P, et al. Percutaneous insertion of the pulmonary valve. J Am Coll Cardiol. 2002;39: 1664-9.

17. Bonhoeffer P, Boudjemline Y, Saliba Z, Hausse AO, Aggoun Y, Bonnet D, et al. Transcatheter implantation of a bovine valve in pulmonary position: a lamb study. Circulation. 2000;102:813-6.

18. Attmann T, Quaden R, Freistedt A, König C, Cremer J, Lutter G. Percutaneous heart valve replacement: histology and calcification characteristics of biological valved stents in juvenile sheep. Cardiovasc Pathol. 2007;16:165-70.

19. Attmann T, Steinseifer U, Cremer J, Lutter G. Percutaneous valve replacement: a novel low-profile polyurethane valved stent. Eur J Cardiothorac Surg. 2006; 30:379. 